\title{
PKM Pelatihan Mengetik Sepuluh Jari bagi Santri Patriot Panji Pelopor (SP3) Pondok Pesantren Nurul Jadid
}

Gulpi Qorik Oktagalu Pratamasunu ${ }^{1}$, Latifatul Khoer ${ }^{2}$, Meliana Eka Puteri ${ }^{3}$, Zumrotul Maqfiroh ${ }^{4}$, Yunis Hofifah' ${ }^{5}$, Siti Umairah ${ }^{6}$, Nidia Fachrum F. Paputungan 7 , Zahrotunnisa Zahrotunnisa ${ }^{8}$

Universitas Nurul Jadid ${ }^{12345678}$

Submission: 16/07/2021 Received: 30/08/2021 Published: 31/12/2021

\begin{abstract}
Keywords:
Training,

Abstract. Currently, ten-finger typing skills have become the general

Skills, standard for prospective employees who will apply for jobs. These

Ten-finger Typing skills are not only needed for IT-based jobs, but are also needed in other jobs in the office. Unfortunately, until now, many students still do not have these skills. Therefore, ten-finger typing training for students at the Nurul Jadid Islamic Boarding School is very much needed.
\end{abstract}

Katakunci:

Latihan,

Kemampuan,

Mengetik sepuluh jari

\begin{abstract}
Abstrak. Saat ini, keahlian mengetik sepuluh jari sudah menjadi standar umum bagi calon pegawai yang akan mendaftar pekerjaan. Keahlian tersebut tidak hanya dibutuhkan untuk pekerjaan berbasis IT saja, tetapi juga dibutuhkan dipekerjaan lain di perkantoran. Sayangnya, hingga saat ini, banyak santri yang masih belum memiliki skill tersebut. Oleh karena itu, pelatihan mengetik sepuluh jari bagi santri di Pondok Pesantren Nurul Jadid sangat dibutuhkan.
\end{abstract}

\section{Pendahuluan}

Perkembangan teknologi yang sangat pesat terutama di perkantoran tentunya membutuhkan pekerja yang memiliki bakat, kemampuan yang tanggap dan cerdas dalam menyelesaikan tugas-tugas tersebut (Ninghardjanti, 2018). Dalam dunia perkantoran tentunya penguasaan terhadap aplikasi-aplikasi perkantoran seperti Ms Excel, Ms Word, dan lain sebagainnya sangat diperlukan.

Untuk menggunakan aplikasi-aplikasi perkantoran tersebut secara efektif tentunya pengguna harus menguasai skill mengetik sepuluh jari. Mengetik sepuluh jari sendiri merupakan keahlian atau keterampilan yang sangat penting dan dibutuhkan untuk pekerjaan yang berbasis IT dengan kompetensi 
keahlian OTKP (Perkantoran) (Ninghardjanti, 2018). Menguasi skill mengetik sepuluh jari sangat mudah jika mengetahui cara yang tepat.

Saat ini, santri di Pondok Pesantren Nurul Jadid sangat minim pengetahuan tentang teknologi, terutama dalam mengetik sepuluh jari. Hal ini dikarenakan para santri tidak diperbolehkan menggunakan gadget dan dibatasi penggunaan laptop ataupun komputer. Permasalahan ini menyebabkan kurangnya daya saing santri yang ingin mencari pekerjaan jika dibandingkan dengan pencari pekerjaan lainnya yang telah memiliki pegetahuan tentang teknologi.

Berdasarkan permasalahan di atas, maka diusulkan pengabdian kepada masyarakat berupa pelatihan mengetik sepuluh jari, untuk meningkatkan skill dalam mengetik sepuluh jari. Selain itu, hal ini juga Menjadi bekal untuk mereka ketika terjun dalam dunia kerja bidang administrasi perkantoran (Sulastri, 2014). Dengan demikian, para santri dapat bersaing dengan pegawai-pegawai atau lulusan dari universitas lainnya.

\section{Metode}

Pelaksanaan kegiatan penelitian dan pengabdian dilaksanakan pada tanggal 4 Maret- 6 April 2021 dan terdapat sekitar 30 orang Santri Patriot Panji Pelopor(SP3) yang ikut bergabung dalam kegiatan pengabdian ini. Sebelum pelaksanaan pengabdian ini kami sudah mendapatkan izin dari pihak terkait untuk melakukan kegiatan pelatihan mengetik sepuluh jari bagi Santri Patriot Panji Pelopor (SP3). Metode yang digunakan dalam pelaksanaan kegiatan ini adalah metode pelatihan berbasis praktek. Adapun tahapan kegiatannya terdiri dari tahap perencanaan dan persiapan, tahap pelaksanaan, dan tahap evaluasi.

Pada tahap perencanaan dan persiapan, kegiatan yang dilakukan adalah menginstal aplikasi yang diperlukan dalam kegiatan pengabdian yaitu Typing Master Pro dan Typer Shark Deluxe. Selanjutnya tim ini yang akan berkolaborasi dan melakukan pengarahan serta pendampingan tentang bagaimana mempraktekkan langsung menggunakan aplikasi mengetik sepuluh jari kepada Santri Patriot Panji Pelopor (SP3).

Tahap pelaksanaan, mencakup kegiatan-kegiatan pengabdian kepada masyarakat dengan melakukan pelatihan mengetik sepuluh jari kepada 
anggota SP3. Tahap evaluasi, selama kegiatan berlangsung, tim penelitian juga melakukan evaluasi terhadap proses pelaksanaan kegiatan ini. Evaluasi dilakukan terhadap peningkatan kemampuan mengetik sepuluh jari kepada santri SP3.

\section{Hasil}

Kegiatan pengabdian ini dilaksanakan pada tanggal 4 Maret- 6 April 2021. Mitra dari kegiatan ini yaitu Santri SP3 Pondok Pesantren Nurul Jadid. Para peserta yang terlibat dalam kegiatan ini sebanyak 30 santri. Kegiatan pengabdian ini dilakukan langsung di Universitas Nurul Jadid, Probolinggo. Pada tahap perancangan dan persiapan, tim memberikan aplikasi berupa Typing Master Pro dan Typer Shark Deluxe kepada santri SP3 untuk diinstal dan dijelaskan cara penggunaannya. Gambar 1 menunjukkan pertemuan pertama serta pengenalan aplikasi oleh tim. Gambar 2 menunjukkan tim yang membantu peserta dalam proses instalasi.

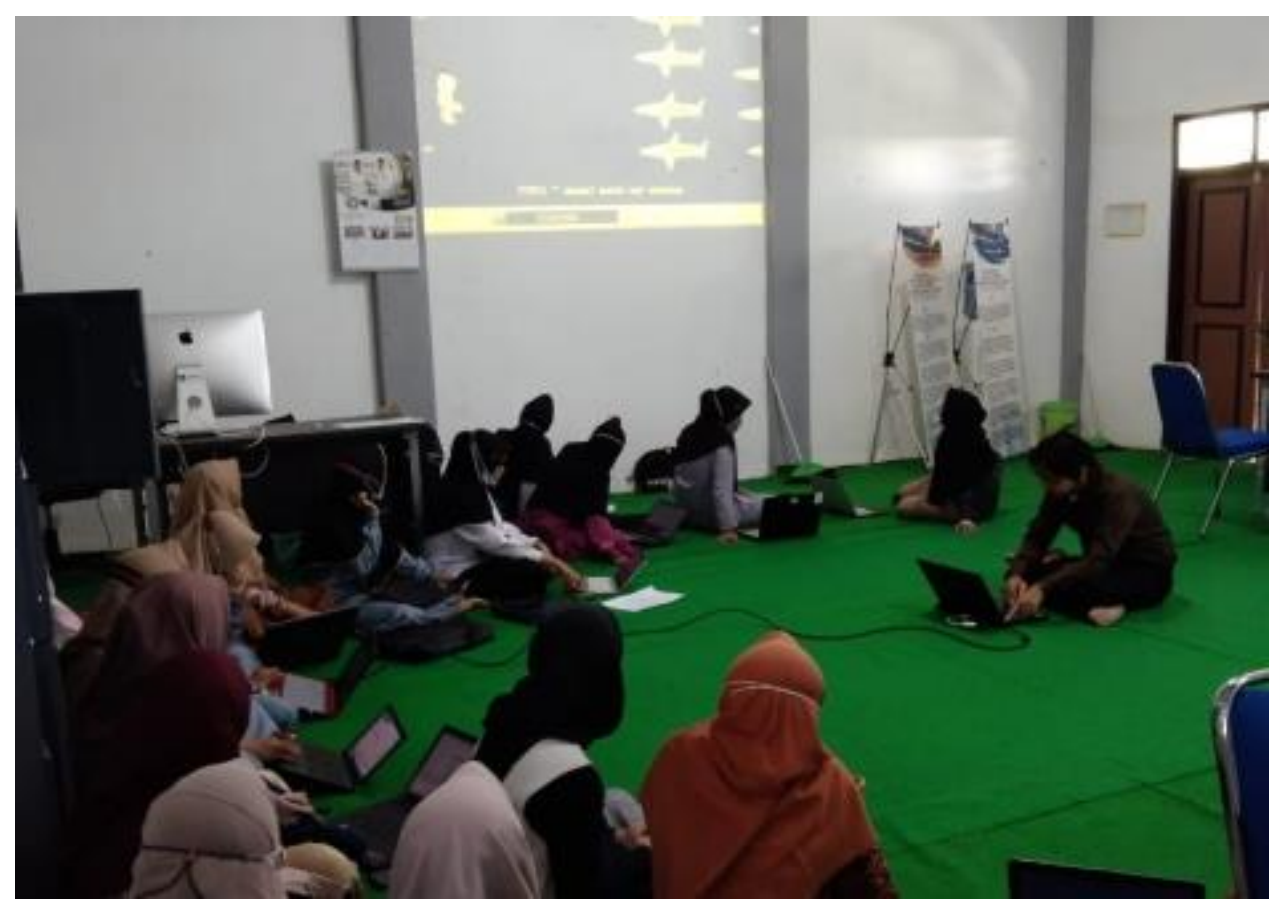

Gambar 1. Pertemuan pertama serta pengenalan aplikasi oleh tim 


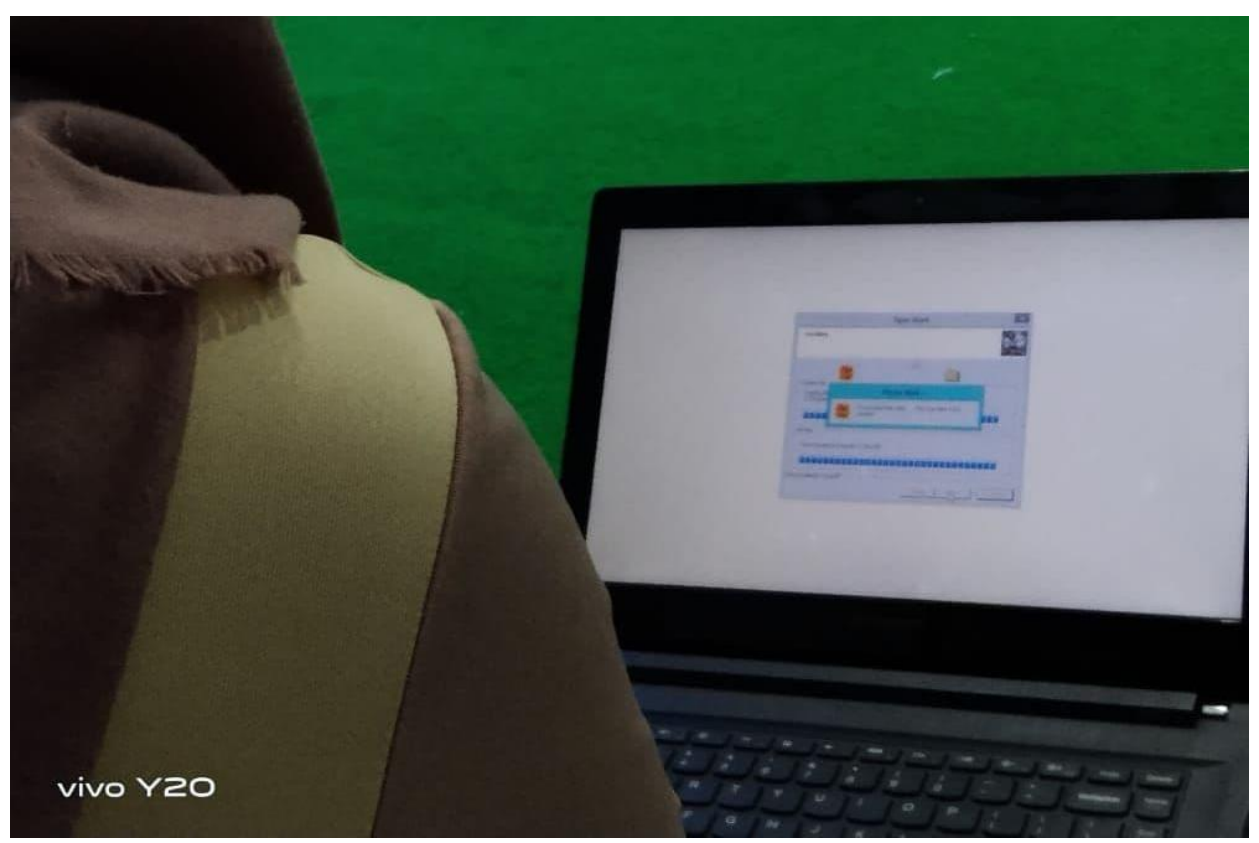

Gambar 2. Proses penginstalan aplikasi

Aplikasi pertama yang digunakan yaitu Typing Master Pro. Typing Master Pro merupakan sebuah software yang dapat melatih kecepatan mengetik sepuluh jari). Tampilan Typing Master Pro ditunjukkan pada Gambar 3. Didalam Aplikasi ini disediakan berbagai jenis permainan yang dapat digunakan untuk mengukur kecapatan dalam mengetik. Tidak hanya itu saja, didalam aplikasi ini juga kita dapat melihat hasil dari kemampuan mengetik, yaitu kecepatan, keakuratan, dan durasi waktu yang digunakan (Alhadi dkk, 2016). Typing Master Pro sangat mudah digunakan dan dipahami, karena kita akan diajarkan dari huruf per huruf dan jari mana yang sesuai dengan huruf yang akan ditekan dan kita hanya mengikuti petunjuk yang diberikan.

Cara instalnya adalah sebagai berikut:

1. Download file aplikasi Typing Master Pro.

2. Jika sudah silahkan buka folder filenya dan klik kanan Run As Adminisator pada ikon Typing Master.

3. Kemudian kita bisa menentukan bahasa apa yang akan digunakan dalam aplikasi, lalu pilih tombol next terus menerus. Jika sudah, klik tombol Finish yang pertanda proses instalasi telah selesai. 


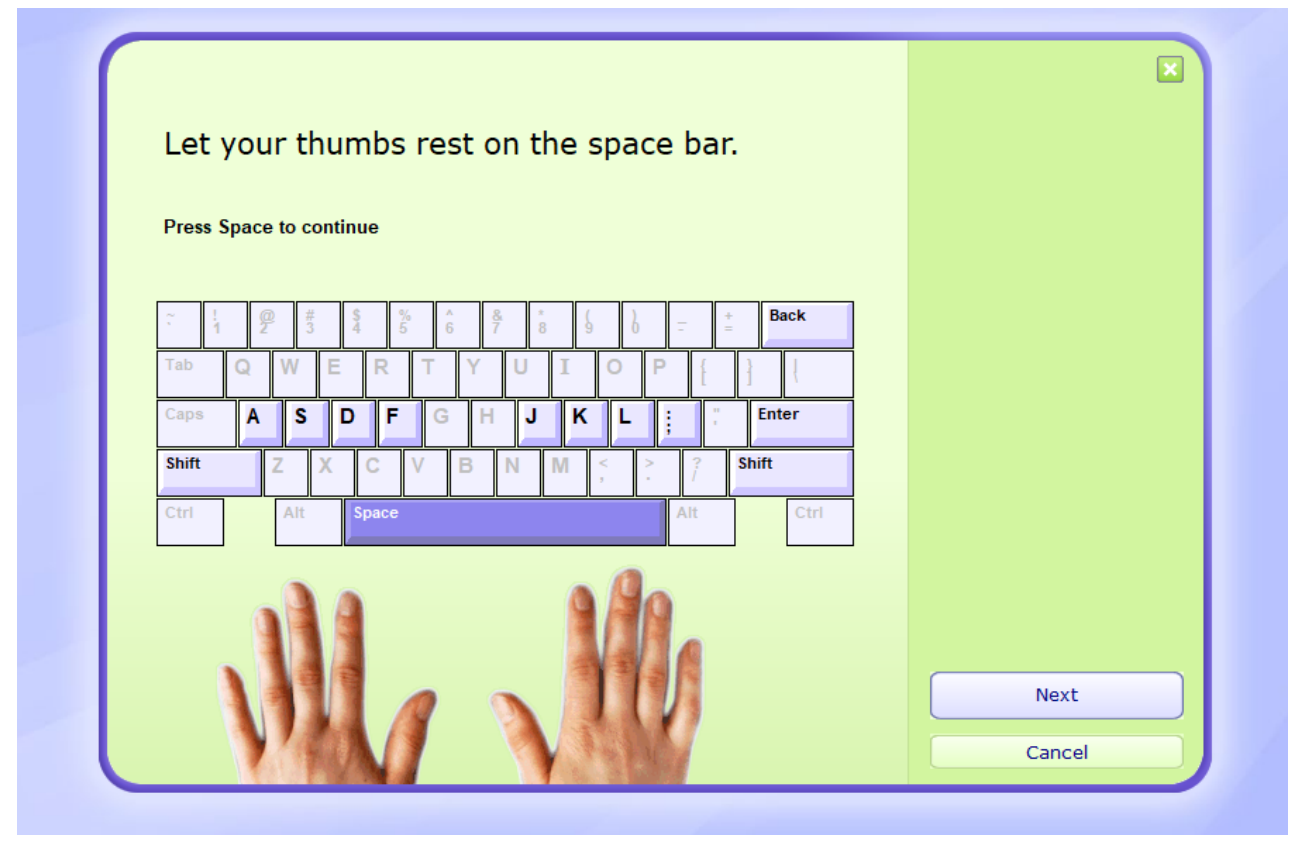

Gambar 3. Aplikasi Typing Master Pro

Aplikasi selanjutnya yaitu Typer Shark Deluxe. Typer Shark Deluxe merupakan sebuah game karya Popcap.com. yang dapat melatih agar cepat dalam mengetik sepuluh jari (Nafiah, 2015). Aplikasi ini juga berisi 3 mode permainan yang bisa digunakan. Untuk mahir dalam mengetik sepuluh jari bisa menggunakan mode typing tutor. Tampilan game Typer Shark Deluxe ditunjukkan pada Gambar 4.

Cara instalnya adalah sebagai berikut:

1. Download Typer Shark Deluxe

2. Setelah mengunduh file, buka folder yang berisi file instalasi dan klik dua kali

3. Ketika jendela pengaturan aplikasi terbuka, klik Ubah Pengaturan untuk mengubah folder yang berisi permainan jika Anda mau.

4. Selanjutnya, klik Browse dan ubah folder yang berisi permainan di jendela kecil di sebelah kiri. Kemudian klik Next.

5. Selanjutnya, klik Saya Setuju untuk menyetujui ketentuan produsen. 
6. Tunggu proses instalasi selesai dan terakhir, klik Done untuk menyelesaikan program instalasi.

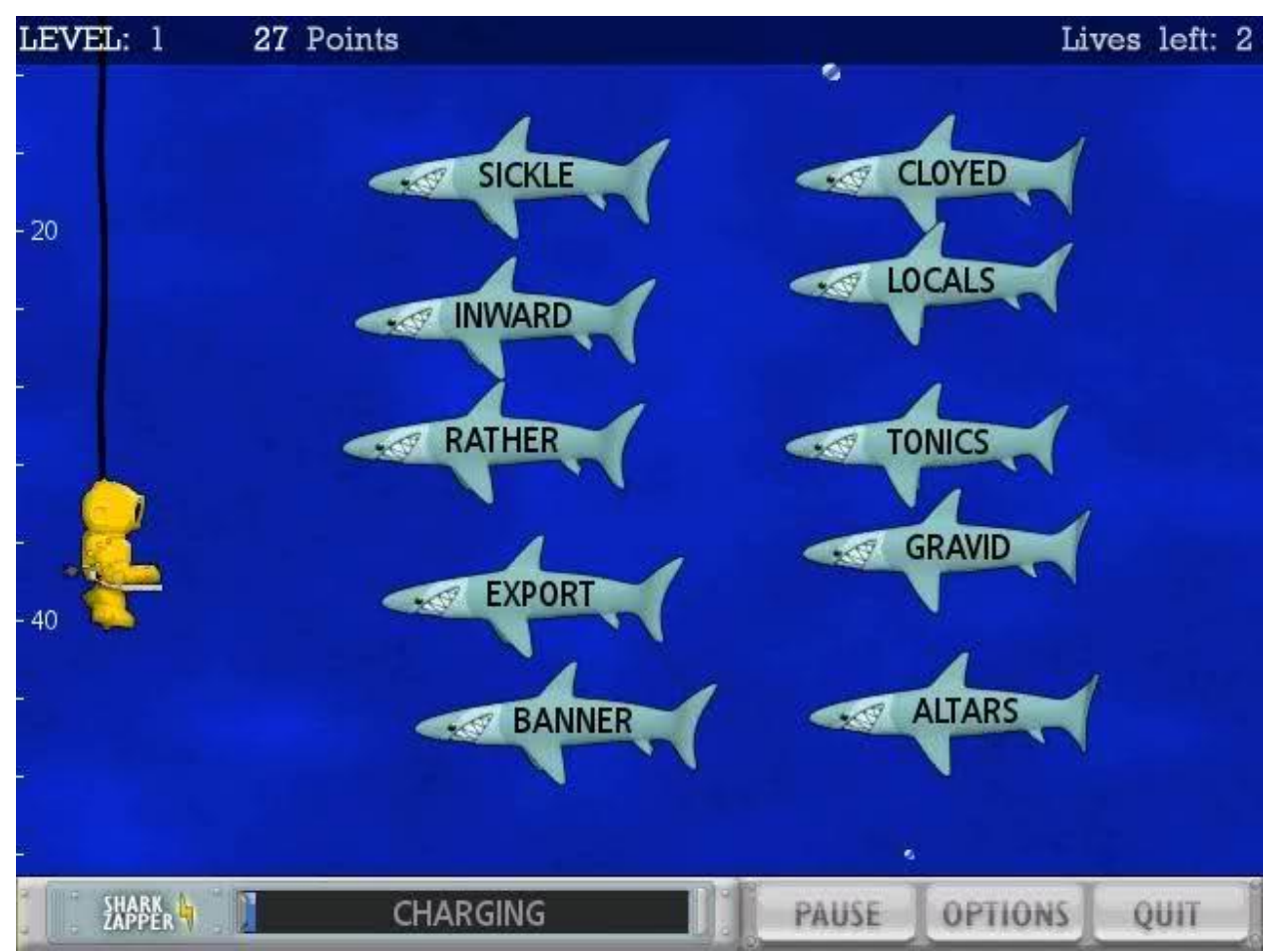

Gambar 4. Aplikasi Typer Shark Deluxe

Tahap selanjutnya adalah tahap pelaksanaan kegiatan pengabdian. Di awal dilakukan tes terlebih dahulu tentang kemampuan mengetik dari para santri. Tes dilakukan dengan menggunakan aplikasi online. Hal ini dilakukan untuk semua peserta. Setiap tes menghasilkan skor. Para peserta bersaing ingin mengalahkan skor peserta lain seperti yang ditunjukkan oleh Gambar 5. Setelah ditampilkan skor dari orang yang bisa mengetik sepuluh jari, mereka semakin ingin untuk belajar mengetik sepuluh jari. Para santri antusias mengikuti pelatihan ini karena tidak pernah ada diajarkan di sekolah atau perkuliahan seperti yang ditunjukkan pada Gambar 6. Proses pelaksanaan pelatihan ini dipantau langsung oleh tim seperti yang ditunjukkan pada Gambar 7. 


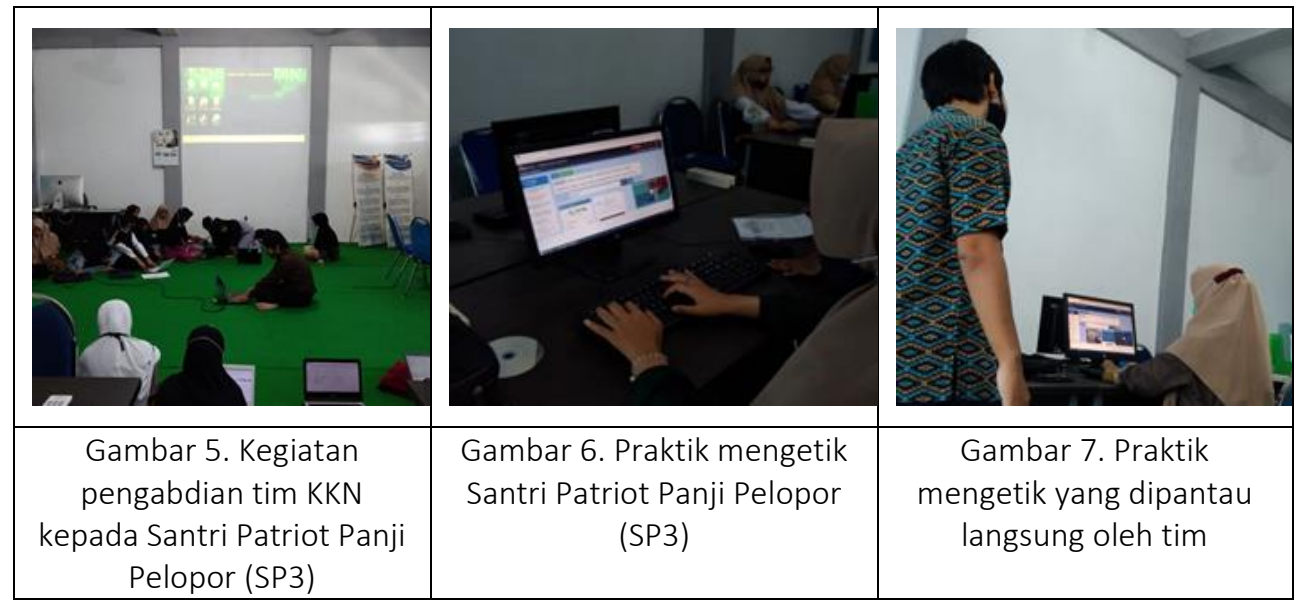

Tahap selanjutnya adalah tahap evaluasi. Para peserta mengalami peningkatan dalam kecepatan mengetik. Yang sebelumnya menggunakan dua jari, pada akhir pertemuan dapat memanfaatkan semua jarinya untuk mengetik. Dikarenakan adanya pandemi, pertemuan tidak bisa dilangsungkan dalam durasi waktu yang lama sehingga beberapa materi tidak tersampaikan.

\section{Pembahasan}

Pada saat pelaksanaan kegiatan, setelah santri melakukan tes mengetik ditunjukkan skor orang yang menguasai kemampuan mengetik sepuluh jari. Dari skor tersebut, para peserta menyadari bahwa skor yang didapatkan jauh di bawah orang yang dapat mengetik sepuluh jari (Indrawati, 2018). Hal ini memotivasi para santri untuk berlatih mengetik sepuluh jari. Pada saat proses pelatihan pengetikan sepuluh jari, peserta tidak merasa terbebani dan mengikuti proses pelatihan dengan senang. Hal ini dikarenakan cara yang digunakan bukanlah cara konvensional melainkan menggunakan praktek secara langsung di aplikasi Typing Master dan game Typer Shark di laptop masing-masing. Dari pemanfaatan aplikasi tersebut terdapat beberapa santri yang mengalami peningkatan skor mengetik cepat.

Berdasarkan praktek rutin dari anggota SP3, mereka dengan sendirinya bisa berlatih dengan menggunakan aplikasi yang telah disediakan sebelumnya yang pastinya mempermudah dalam meningkatkan kecepatan dan akurasi dalam mengetik. Dengan semakin sering berlatihnya mereka, 
maka diperoleh hasil observasi bahwa skil mereka pun dari hari ke hari semakin bertambah dan mulai terbiasa.

Diharapkan dengan dilakukannya kegiatan ini, santri Pondok Pesantren Nurul Jadid, memiliki media yang tepat dan menyenangkan untuk belajar mengetik sepuluh jari. Selain itu, kemampuan ini dapat diterapkan dalam dunia kerja nantinya. Hal ini diperkuat dengan penelitian dari Sukirno (Sukirno, 2014) bahwa kemampuan mengetik sepuluh jari berpengaruh kepada kemampuan pegawai administrasi.

\section{Kesimpulan}

Kemampuan menulis sesuatu akan semakin mudah dan cepat jika didukung oleh kemampuan mengetik yang baik. Dengan memiliki kemampuan mengetik sepuluh jari, yang diperlukan hanyalah fokus terhadap kata atau kalimat yang akan diketik tanpa memikirkan tata letak huruf pada keyboard.

Pengabdian berupa pelatihan ini sangat berguna bagi Santri Patriot Panji Pelopor (SP3) Pondok Pesantren Nurul Jadid agar nantinya skill mengetik sepuluh jari yang dikuasai dapat bersaing dengan pekerja-pekerja lain. Selain itu, skill tersebut memudahkan mereka dalam menyelesaikan tugas yang berhubungan dengan mengetik. Kemampuan dalam mengetik sepuluh jari harus selalu ditingkatkan agar skill yang dimiliki lebih baik dan dapat semakin cepat dalam mengetik.

\section{Referensi}

Alhadi, E., Andriyani, T., \& Z, M. (2016). Penerapan Program Typing Master Dalam Meningkatkan Kecepatan Dan Ketelitian Pengetikan 10 Jari Buta. Orasi Bisnis: Jurnal Ilmiah Administrasi Niaga, 16(2).

Nafiah, D. (2015). Peran Typer Shark Deluxe Sebagai Media Pembelajaran Mengetik Cepat Bagi Calon Sekretaris. Jurnal Efisiensi: Kajian IImu Adminitrasi, 13(2), 1-13.

Ninghardjanti, P., Yuwantiningsih, A. (2018). Peningkatan Kecepatan Mengetik 10 Jari Melalui Penerapan Metode Drill Dan Resitasi (Pada Peserta Didik Kelas X Ap 1 SMK Negeri 1 Surakarta Tahun Pelajaran 
2018/2019). Prosiding Seminar Nasional Pendidikan Administrasi Perkantoran (SNPAP) 2018, 7-13.

Sulastri, T. (2014). Analisis Mengetik Cepat 10 Jari Menggunakan Teknologi Komputer Berbasis Aplikasi Software Rapidtyping. JURNAL LPKIA, 4(2).

Sukirno. (2014). Korelasi Kemahiran Mengetik Sepuluh Jari Terhadap Kinerja Staf Administrasi di ASM Bina Insani. Jurnal Administrasi Kantor, 2(1), hal. 307-325.

Indrawati, C, D, S., Rozi, U, A., Widodo, J. (2018) Pemanfaatan Program Aplikasi Typing Master Untuk Meningkatkan Kecepatan Mengetik Siswa SMK Wikarya Karanganyar Tahun 2018/2019. Jurnal Informasi dan Komunikasi Admonistrasi Perkantoran.

Dean, A, A, D. (2020) Media Pembelajaran Interaktif Simulasi Mengetik 10 Jari. Jurnal Fasikom 10 (2), 139=143, 2020.

Setyaningsih, L, H. (2014) Peningkatan Keterampilan Mengetik Sistem 10 Jari Buta dengan Menggunakan Model Pembelajaran Berbasis Komputer Berbantu Media Typing Master Pada Siswa Kelas Kelas X AP SMK Muhammadiyah 01 Pati. Economc Edication Analysis Journal 3 (1), 2014. 